\title{
Critical disparities in perinatal health-understanding risks and changing the outcomes
}

\author{
Leslie M. Harris ${ }^{1} \cdot$ Zaneta Forson-Dare $^{1} \cdot$ Patrick G. Gallagher ${ }^{1}$
}

Received: 2 December 2020 / Revised: 8 December 2020 / Accepted: 8 December 2020 / Published online: 18 January 2021

(c) The Author(s), under exclusive licence to Springer Nature America, Inc. 2021

Structural racism is woven in the fabric of our society, including our healthcare system. It impacts health at every level, from bedside interactions of healthcare workers with patients and their families to large-scale disparities in morbidity and mortality. In the next two issues of the Journal of Perinatology, collections of articles highlight some of these health inequities and their effect on mothers and their babies. This month's issue focuses on the broad scope of racial health disparities in perinatal outcomes. Next month's issue will explore specific ways that providers can advocate for racial justice in their practice as well as highlight other disparities related to ethnicity and gender.

Health inequity caused by systemic racism has been declared a public health emergency by many groups, including medical associations and local and state governments. Black people, on average, die 3.5 years sooner than White people and Black men have an average life expectancy more than 4 years less than White men [1]. Black women are 2-3 times more likely to die because of pregnancy-related complications than White women [2]. These are differences in mortality-people are dying. The roots of these disparities are deeper than the healthcare system. As shown by David and Collins [3] and Yang et al. [4] in this issue, structural racism has led to income, housing, education, and environmental inequities that disproportionately affect Black people. Inequities in health and other social factors begin before a child is born and continue after birth, influencing health across the entire lifespan.

Perinatal medicine is full of conflicting or insufficient evidence for many of our practices. However, in the case of the effects of systemic racism on mothers and their neonates, data clearly demonstrating racial disparities in

Patrick G. Gallagher

patrick.gallagher@yale.edu

1 Division of Neonatal/Perinatal Medicine, Department of Pediatrics, Yale University School of Medicine and Yale New Haven Children's Hospital, New Haven, CT, USA perinatal care and outcomes have been available for decades. As highlighted by Dongarwar et al. [5] and Tomlin et al. [6] as well as Montoya-Williams et al. [7], Black infants are $>2$ times more likely to die than White infants [8] and are more likely to be born premature and low birth weight [9]. As Karvonen et al. [10] describe, Black preterm infants go on to experience health disparities beyond the NICU. These pervasive disparities in preterm birth and infant mortality have persisted despite advances in neonatal care and programs designed to address these issues.

Perinatal care providers are familiar with vulnerable populations. It is time to leverage both the experience of experts in the field and data-driven scientific methods to address racial health inequities. Race is not a risk factorrace is a social construct. Deep-rooted systemic racial injustices and racism are the risk factors. The authors of the articles in this issue provide data showing that racial disparities in neonatal and perinatal outcomes are ongoing and complex, involving disparities in healthcare, socioeconomic resources, toxic stress, and more. In combination with the articles in the following issue, they provide evidence of the critical need for a multidisciplinary approach of dedicated research, provider education, and advocacy in partnership with patients and families in the work to eliminate racial disparities in neonatal and perinatal health. It is essential that we change the outcomes. Lives depend on it.

\section{Compliance with ethical standards}

Conflict of interest The authors declare that they have no conflict of interest.

Publisher's note Springer Nature remains neutral with regard to jurisdictional claims in published maps and institutional affiliations.

\section{References}

1. Kochanek KD, Murphy SL, Xu JQ, Arias E. Deaths: Final data for 2017. National Vital Statistics Reports. Hyattsville, MD: National 
Center for Health Statistics; National Vital Statistics Reports. Vol. 68, p. 1-77. 2019. https://stacks.cdc.gov/view/cdc/79486. Accessed 1 Dec 2020.

2. Petersen EE, Davis NL, Goodman D, Cox S, Syverson C, Seed K, et al. Racial/ethnic disparities in pregnancy-related deathsUnited States, 2007-2016. Morbidity Mortal Wkly Rep. 2019;68:762.

3. David R, Collins JW. Why does racial inequity in health persist? J Perinatol. 2021;41, in press.

4. Yang N, Collins JW, Burris HH. States with more killings of unarmed black people have larger black-white preterm birth disparities. J Perinatol. 2021;41, in press.

5. Dongarwar D, Tahseen D, Wang L, Aliyu MH, Salihu HM. Temporal trends in preterm birth phenotypes by plurality: black-white disparity over half a century. J Perinatol. 2021;41, in press.

6. Tomlin BD, McAdams RM, Zapata JY, Kaluarachchi DC. High black infant mortality in Wisconsin: factors associated with the ongoing racial inequity. J Perinatol. 2021;41, in press.
7. Montoya-Williams D, Passarella M, Grobman W, Lorch S. Racial/ ethnic differences in maternal resilience and associations with low birthweight. J Perinatol. 2021;41, in press.

8. Ely DM, Driscoll AK. Infant Mortality in the United States, 2018: Data From the Period Linked Birth/Infant Death File. National Vital Statistics Reports: From the Centers for Disease Control and Prevention, National Center for Health Statistics, National Vital Statistics System. 2020;69:1-18. https://www.cdc.gov/nchs/data/ nvsr/nvsr69/NVSR-69-7-508.pdf. Accessed 1 Dec 2020.

9. Martin JA, Hamilton BE, Osterman MJK, Driscoll AK. Births: Final data for 2018. National Vital Statistics Reports. Hyattsville, MD: National Center for Health Statistics; Vol. 68, p. 1-47. 2019. https://stacks.cdc.gov/view/cdc/82909. Accessed 2 Dec 2020.

10. Karvonen KL, Baer RJ, Rogers EE, Steurer MA, Ryckman KK, Feuer SK, et al. Racial and ethnic disparities in outcomes through one year of life in infants born prematurely: a population based study in California. J Perinatol. 2021;41, in press. 